\title{
Multiplex immunohistochemistry for immune profiling of HPV-associated head and neck cancer
}

\author{
Takahiro Tsujikawa', Rohan N Borkar², Vahid Azimi², El Edward Rassi ${ }^{1}$, Daniel R Clayburgh', Sushil Kumar ${ }^{1}$, \\ Andrew J Gunderson ${ }^{1}$, Molly F Kresz-Martin ${ }^{1}$, Paul W Flint ${ }^{1}$, Lisa M Coussens ${ }^{1 *}$ \\ From 30th Annual Meeting and Associated Programs of the Society for Immunotherapy of Cancer (SITC 2015) \\ National Harbor, MD, USA. 4-8 November 2015
}

Human Papilloma Virus (HPV)-positive head and neck squamous cell carcinoma (HNSCC) is clinically distinct from HPV-negative HNSCC, and as such requires differential therapeutic approaches. Accumulating evidence indicates a significant linkage between the immune response within the tissue and pathogenesis of HPVassociated HNSCC. To further elucidate immune-related signatures in HPV-associated HNSCC, we performed multiplex histological analysis in de-identified tissue microarray sections including HPV-positive $(\mathrm{n}=21)$, HPV-negative $(\mathrm{n}=17)$, and normal oropharynx $(\mathrm{n}=8)$. Following immunohistochemistry (IHC) for CD45, CD3, CD8, Foxp3, T-bet, GATA-3, RORgT, CD20, CD56, CD68, MHC class II, CSF1R, CD66b, tryptase, CD83, DC-SIGN, PD-1, and PD-L1, the cell intensity per $\mathrm{mm}^{2}$ ratio/composition, localization were quantitatively evaluated. The HPV-status was confirmed by HPV16/18 polymerase chain reaction and IHC for $\mathrm{p} 16^{\mathrm{INK} 4 \mathrm{a}}$. IHC for p16 or EpCAM were utilized for defining tumor region. Infiltration of $\mathrm{T}$ cell populations including $\mathrm{CD} 45^{+} \mathrm{CD} 3$ ${ }^{+} \mathrm{CD} 8^{+} \mathrm{T}$ cells $(P<0.01), \mathrm{CD} 45^{+} \mathrm{CD} 3^{+} \mathrm{CD}^{-} \mathrm{Foxp}^{+}$regulatory $\mathrm{T}$ cells $(P<0.05)$ and $\mathrm{CD} 45^{+} \mathrm{CD} 3^{+} \mathrm{CD} 8^{-} \mathrm{Foxp} 3^{+} \mathrm{T}$ bet $^{+}$Th1 cells $(P<0.01), \mathrm{CD} 45^{+} \mathrm{CD} 20^{+} \mathrm{CD} 3^{-} \mathrm{B}$ cells $(P<$ $0.05), \mathrm{CD} 45^{+} \mathrm{CD} 68^{+} \mathrm{CD} 163^{-}$macrophages $(P<0.001)$, and CD $45^{+}$Tryptase $^{+}$mast cells $(P<0.01)$ was significantly higher in the HPV-positive group than in the HPV-negative group. CD8/CD68 ratio of HPV-positive tumor was higher than that of HPV-negative tumor $(P<0.05)$, and the highest $\mathrm{CD} 163^{-} \mathrm{CD} 68^{+} / \mathrm{CD} 163^{+} \mathrm{CD} 68^{+}$ratio was observed in the intra-tumor region of HPV-positive tumors. High $\mathrm{PD}-\mathrm{L} 1$ expression on $\mathrm{CD} 68^{+} \mathrm{CD} 163^{+}$macrophages and MHC class $\mathrm{II}^{+} \mathrm{CD} 83^{+}$dendritic cells was intensively observed in the intra-tumor region of the HPV-positive group while maturation of dendritic cells assessed by CD83/DC-SIGN ratio was significantly higher in the peritumoral stroma than intra-tumor regions $(P<0.05)$, indicating distinct immune regulatory mechanisms between intra and peritumoral regions. These signatures provide further evidence of anti-tumor immunity against HPV-positive head and neck cancer, and potentially lead to personalized treatment including immunomodulatory therapeutic targets specialized for the HPV/ immune status.

\section{Acknowledgements}

This project was supported by Oregon Clinical and Translational Research Institute (OCTRI), grant number (UL1TR000128) from the National Center for Advancing Translational Sciences (NCATS) at the National Institutes of Health (NIH), and OHSU Knight Cancer Institute, grant number P30 CA069533-17. LMC acknowledges support from the NIH/NCl, DOD BCRP Era of Hope Scholar Expansion Award, Susan B. Komen Foundation, Stand Up To Cancer - Lustgarten Foundation Pancreatic Cancer Convergence Dream Team Translational Research Grant, and Brenden-Colson Center for Pancreatic Health.

\section{Authors' details}

'Oregon Health \& Science University, Portland, OR, USA. ${ }^{2}$ Intel Corporation, Hillsboro, OR, USA.

Published: 4 November 2015

doi:10.1186/2051-1426-3-S2-P419

Cite this article as: Tsujikawa et al: Multiplex immunohistochemistry for immune profiling of HPV-associated head and neck cancer. Journal for ImmunoTherapy of Cancer 2015 3(Suppl 2):P419.

Oregon Health \& Science University, Portland, OR, USA

Full list of author information is available at the end of the article 